\title{
SAÚDE DIGITAL E OS DESAFIOS REGULATÓRIOS
}

\section{Digital health and regulatory challenges}

O século XXI encontra-se plenamente inserido na chamada Era Digital, marcada pela mudança da revolução industrial para um novo domínio econômico e social baseado na tecnologia da informação, que vem transformando intensamente o próprio conhecimento humano, influenciando a comunicação entre as pessoas, as interações sociais, a organização da sociedade civil e da própria democracia, bem como a circulação de ideias, serviços e produtos relacionados com a saúde individual e coletiva.

As inovações tecnológicas da Era Digital que atingem o setor da saúde são de proporções amazônicas: internet, grandes bases de dados, aprendizado automatizado, inteligência artificial, alta conectividade, redes sociais digitais globais, grandes corporações digitais, telessaúde, dentre outras várias novidades já existentes ou no forno para sair. Esses novos componentes da vida moderna digital estão revolucionando com grande intensidade o setor. Um enorme número de bens, produtos e serviços que se utilizam destes bancos de dados e tecnologias está sendo lançado nos sistemas de saúde do mundo todo.

Hoje podemos encontrar diversos exemplos desse novo fenômeno: equipamentos médicos com inteligência artificial e capacidade de realizar cirurgias complexas apenas com a supervisão humana; dispositivos laboratoriais de diagnóstico que se utilizam da nuvem de dados digitais e da inteligência artificial para laudos diagnósticos conclusivos; bases de dados gigantes, organizadas e de "propriedade" de grandes grupos corporativos privados, com alto potencial de lucro em sua utilização (monetização das bases de dados digitais); dispositivos médicos capazes de realizar anamnese, diagnóstico e, ainda, fazer uma proposta terapêutica para o paciente; aplicativos de internet que captam dados sensíveis das pessoas e prescrevem dicas ou orientações de comportamentos no campo da saúde física e mental. Enfim, as inovações não param de surgir.

Esse conjunto abrangente de produtos e serviços de saúde que se utilizam das novas tecnologias digitais vem formando um campo de estudo que, genericamente, está sendo denominado como "saúde digital". No âmbito da saúde digital, a inteligência artificial destaca-se como um dos grandes temas a ser compreendido e regulado. 
Para além dos benefícios enormes que estas inovações trazem, já está evidenciado que esses produtos e serviços, se não fiscalizados e desenvolvidos com ética e responsabilidade, podem produzir danos físicos, psicológicos e morais nos seus usuários. Compreender os desafios regulatórios impostos à sociedade nesse momento mostra-se estratégico para que possamos usufruir dos benefícios trazidos por essa inovações, sem contudo expor os indivíduos e a sociedade como um todo a riscos desnecessários e até letais.

O Direito Sanitário deve, assim, manter-se alerta sobre esse novo fenômeno do setor saúde, para acompanhar de perto sua evolução e poder cooperar com a sociedade no sentido de organizar uma ação estatal e social adequada para que essas inovações sejam benéficas e contenham o mínimo de riscos à saúde humana possível.

Desde a segurança dos equipamentos médicos e hospitalares que se utilizam da saúde digital, passando pela garantia de acesso às inovações tecnológicas que vão sendo incorporadas ao sistema de saúde, até o misterioso e desregulado ambiente onde se desenvolvem e são testados os algoritmos de inteligência artificial em saúde, as funções regulatórias do Estado se impõem de forma inequívoca.

No Brasil, a Lei Geral de Proteção de Dados (LGPD), Lei n. 13.709/2018, com destaque para as normas de proteção dos direitos de personalidade e a criação da Autoridade Nacional de Proteção de Dados, configura um importante avanço institucional e regulatório em relação à saúde digital. Contudo, seguem incipientes tanto a regulação como a legislação vigente sobre o tema no país.

Some-se a esse cenário a frágil organização institucional e de governança estatal para o eficiente exercício do poder regulatório no campo da saúde digital e percebemos a imperiosa necessidade de se construir um ambiente regulatório que seja capaz de, ao mesmo tempo, oferecer as bases necessárias para o desenvolvimento de novas tecnologias benéficas à sociedade e aos pacientes e estabelecer os limites destas novas tecnologias no que se refere à plena proteção dos direitos fundamentais do ser humano, notadamente a integridade física e psicológica, a intimidade, a privacidade, a saúde e a liberdade.

Fernando Aith

Editor-Chefe 